\title{
The radiation protection role of heparin-SOD conjugate in irradiated mice
}

\author{
Chuanqing Zhong, ${ }^{1,2}$, Xiaojing Huang ${ }^{1,3}$, Shu Zhang1, Yanna Cheng ${ }^{1}$, Guangxiang Cao ${ }^{4}$, \\ Fengshan Wang,*
}

\begin{abstract}
${ }^{1}$ Institute of Biochemical and Biotechnological Drugs, School of Pharmaceutical Science, Shandong University, China, ${ }^{2}$ School of Municipal and Environmental Engineering, Shandong Jianzhu University, China, ${ }^{3}$ Department of Pharmacy, Henan Provincial People's Hospital, China, ${ }^{4}$ Shandong Medicinal Biotechnology Centre, China
\end{abstract}

\begin{abstract}
Heparin-SOD conjugate (Hep-SOD) was prepared by modifying $\mathrm{Cu}, \mathrm{Zn}$-SOD with heparin. An acute radiation-induced mouse injury model was constructed to study the radiation protection effects of HepSOD conjugate. Fifty-six mice were randomly divided into seven groups: (I) normal control group; (II) irradiated control group; (III) positive control group (amifostine group, $300 \mathrm{mg} / \mathrm{kg}$ ); (IV) SOD group (35000 U/kg); (V) high dosage of Hep-SOD group (70000 U/kg); (VI) medium dosage of Hep-SOD group (35000 U/kg); (VII) low dosage of Hep-SOD group (17500 U/kg). Drugs were intraperitoneally injected into each mouse $1 \mathrm{~h}$ before radiation except for the normal control group. All the irradiated groups were irradiated with 6 Gy. Organ indices, haematopoietic function indices, peripheral blood cells, liver function test, oxidative stress state and pathological observation were detected to study the effects of Hep-SOD on irradiated mice. Results showed that bone marrow suppression of irradiated mice could be reduced when treated by Hep-SOD before radiation. Oxidative stress detection and pathological observation of the liver and intestine showed that the damage caused by radiation was relieved when mice were treated with Hep-SOD before radiation. This study shows a new direction to prevent organisms from the damage caused by radiation.
\end{abstract}

Keywords: Heparin-superoxide dismutase conjugate. Radiation-induced damage. Oxidative stress injury.

\section{INTRODUCTION}

Occurrence of accidents in nuclear power plants, application of nuclear weapons in war and improper disposal of experiment apparatus and medical devices with residual radiation in research institutes and hospitals leave behind much radiation, which may cause serious problems. Radiation may induce various disorders (Alamri et al., 2012; Ma et al., 2014), potentially affecting the function and life of somatic cells, leading to serious diseases including cancer and neurodegenerative diseases (Bioteux, Guillet, 2004; Rooney, Patil, Zappala, 2008). Ultraviolet radiation can also cause DNA damage, which has an impact on human health. Furthermore, radiotherapy can cause damage to normal cells when killing tumour cells (Georg et al., 2009; Bölling et al., 2011; Echeveste, Agustí, Dachs, 2011), which

\footnotetext{
*Correspondence: F. Wang. Institute of Biochemical and Biotechnological Drugs, School of Pharmaceutical Science, Shandong University. Jinan 250012, China. Phone: 0086-531-88382658 / Fax: 86-531-88382548. E-mail: fswang@sdu.edu.cn
}

greatly influences the curative effects on patients. Analysis of genomic instability by testing chromosome aberrations in the offspring of one or both irradiated parents demonstrated significantly higher agglutination factor (AGF) than in the children of non-irradiated parents (Aghajanyan, Suskov, 2009; Aghajanyan et al., 2011) so there is an urgent need to look for new methods of protection against radiationinduced damage.

Previous studies showed that intravenous injection of superoxide dismutase (SOD) into mice could significantly resist the reduction of red blood cells, reticulocytes and white blood cells induced by X-ray (Petkau, Chelack, Pleskach, 1978). SOD has therapeutic effects because it can eliminate superoxide anions, which is important in various diseases regulated by ROS, such as inflammation (Liu et al., 2009a). As one of the anti-radiation-induced damage drugs, $\mathrm{Cu}, \mathrm{Zn}$-SOD has fewer side effects, but its half-life is short. Heparin was reported to induce protein synthesis in fibroblasts (Tyagi, Kumar, Katwa, 1997), and modulate the collagen phenotype of porcine aorta smooth muscle cells 
(Asselot-Chapel et al., 1995) or fibroblasts from radiationinduced subcutaneous fibrosis (Nabout et al., 1989). Heparin can also increase the concentration of $\mathrm{Cu}, \mathrm{Zn}-\mathrm{SOD}$ in the conditioned medium of fibroblasts (Castellot et al., 1985; Adachi et al., 2001). Considering the advantages of both $\mathrm{Cu}, \mathrm{Zn}-\mathrm{SOD}$ and heparin, we chemically modified $\mathrm{Cu}, \mathrm{Zn}$ SOD with heparin (Qi et al., 2006). The immunogenicity of $\mathrm{Cu}, \mathrm{Zn}$-SOD was proved to be lowered and the stability was increased after the modification (Zhang et al., 2006). ${ }^{125}$ I-radiolabelled heparin-SOD (Hep-SOD) conjugate was administered into healthy mice by intravenous (i.v.) bolus injection. Compared with $\mathrm{Cu}, \mathrm{Zn}-\mathrm{SOD}$, the halflife of Hep-SOD conjugate, including $t_{1 / 2 \alpha}$ and $t_{1 / 2 \beta}$, was lengthened and the area under the plasma concentration versus time curve (AUC) of Hep-SOD was increased (Liu et al., 2010b). Hep-SOD conjugate is stable in biological systems (Liu et al., 2010a, b). Our previous studies showed that Hep-SOD conjugate can be delivered in a targeted manner to macrophages, and can attenuate bleomycininduced pulmonary fibrosis, carbon tetrachloride-induced acute liver failure and hepatic fibrosis in mice (Liu et al., 2009a, 2009b, 2009c). Also, Hep-SOD can inhibit DNA damage induced by $\gamma$-radiation. The radiation-induced damage prevention effects of Hep-SOD in vivo are reported more systematically in this paper, including the detection of alanine aminotransferase (GPT), aspartate aminotransferase (GOT), malondialdehyde (MDA) and L-glutathione (GSH).

\section{MATERIAL AND METHODS}

\section{Material}

$\mathrm{Cu}, \mathrm{Zn}-\mathrm{SOD}$ was purchased from Kemaipu Biotechnological Co. Ltd., China. Heparin was provided by Dongcheng Biochemical Co. Ltd., China. Amifostine was purchased from Xinxinjiali Co., Wuhan, China. Q-Sepharose Fast Flow was from GE Healthcare Co. Sodium periodate was from the Kemiou Chemical Reagent Development Centre. Acrylamide and ammonium peroxydisulfate were from Sigma, USA and pyrogallic acid was from Alpha, USA. The BCA assay kit, trypsin solution and penicillin-streptomycin solution were purchased from Biyuntian Co., China. SOD, GPT, GOT, MDA and GSH assay kits were from the Nanjing Jiancheng Bioengineering Institute, China.

\section{Animals and animal grouping}

Male Kunming mice, weighing 23.0-25.0 g, were purchased from the Experimental Animal Centre of Shandong University, and the laboratory animal licence number was SCXK (Shandong) 20090001. The experiment was conducted according to the Guide for Care of Laboratory Animals.

Fifty-six mice were randomly divided into seven groups according to their body weight: (I) normal control group; (II) irradiated control group; (III) positive control group (amifostine group, $300 \mathrm{mg} / \mathrm{kg}$ ); (IV) SOD group (35000 U/kg); (V) high dosage of Hep-SOD group (70000 $\mathrm{U} / \mathrm{kg}$ ); (VI) medium dosage of Hep-SOD group (35000 U/ $\mathrm{kg}$ ); (VII) low dosage of Hep-SOD group (17500 U/kg). Drugs were intraperitoneally injected into each mouse $1 \mathrm{~h}$ before radiation except for the normal control and irradiated control groups. All groups were irradiated except the normal control group. Each group consisted of eight mice.

\section{Preparation of Hep-SOD conjugate}

Hep-SOD conjugate was synthesized according to the method reported previously (Qi et al., 2006; Zhang et al., 2006). The protein content and enzymatic activity of HepSOD were determined by BCA assay kit and SOD assay kit, respectively. The quantity of amino groups was determined by trinitrobenzene sulfonic acid (Habeeb, 1966).

\section{Radiation protection effects of Hep-SOD in vivo}

\section{Establishment of acute radiation-induced mouse injury model}

Mice were radiated in the Atomic Energy Institution of Shandong Academy of Agricultural Science with a ${ }^{60} \mathrm{Co}$ radiation source after each treatment. All mice to be irradiated were grouped in cages. The radiation dosage was $6 \mathrm{~Gy}$ at $1.0 \mathrm{~Gy} / \mathrm{min}$. Each irradiation procedure lasted for $6 \mathrm{~min}$. The distance between the ${ }^{60} \mathrm{Co}$ source and the mice was $80 \mathrm{~cm}$. No sedatives were used before or after the radiation.

\section{Evaluation of radiation protection effects of Hep-SOD in vivo}

Each mouse was weighed on the eighth day after radiation, had blood collected from the retro-orbital plexus (Simonnet et al., 2009) and was put to death. The radiation protection effect of Hep-SOD in vivo was determined as described below.

\section{Organ indices}

The intact thymus and spleen of all the mice were taken and weighed accurately. The thymus index equals the weight of the thymus divided by the body weight and the spleen index equals the weight of the spleen divided by the body weight. 


\section{Haematopoietic function indices}

Splenic nodules (CFU-S)

The spleen from each mouse was put in Bouin solution and fixed for $24 \mathrm{~h}$. The surface of the spleen was washed with $70 \%$ alcohol, and then the CFU-S were counted with the naked eye.

\section{Bone marrow nucleated cells (BMNC)}

The left femur of each mouse was taken and the muscle tissue on the femur was eliminated. The femoral ends were washed with $5 \mathrm{~mL}$ of $3 \%$ glacial acetic acid and the bone marrow cell suspension was collected. The suspension was mixed uniformly to count the BMNC in cell-counting plates.

\section{DNA content in bone marrow}

The right femur was taken from each mouse and the muscle tissue was eliminated. The femoral ends were washed thoroughly with $5 \mathrm{mmol} / \mathrm{L} \mathrm{CaCl}_{2}$. The bone marrow eluate was kept at $4{ }^{\circ} \mathrm{C}$ for $30 \mathrm{~min}$, centrifuged at $2500 \mathrm{r} / \mathrm{min}$ for $15 \mathrm{~min}$ and then the supernatant was discarded (Delanian et al., 1994; Lefaix et al., 1996; Pan et al., 2012); $5 \mathrm{~mL}$ of $0.2 \mathrm{~mol} / \mathrm{L} \mathrm{HClO}_{4}$ was added to the precipitate. The dispersed solution was mixed thoroughly and heated in a $90{ }^{\circ} \mathrm{C}$ water bath for $15 \mathrm{~min}$. The solution was filtered when the samples were cooled to room temperature. DNA content was detected at $\mathrm{A}_{260}$ by UV spectrophotometer (Nornura et al., 2000; Davis et al., 2008).

\section{Counting of peripheral blood cells}

Peripheral blood was taken from each mouse. White blood cells (WBC), red blood cells (RBC), blood platelets (PLT) and lymphocytes (LY) were counted immediately by routine blood examination at Qilu Hospital, Shandong University.

\section{Liver function test}

Peripheral blood was centrifuged at $4{ }^{\circ} \mathrm{C}$ and $3000 \mathrm{r} /$ min for $10 \mathrm{~min}$ and the blood plasma was collected. Then the activity of both GPT and GOT was detected by GPT and GOT detection kits, respectively.

\section{Oxidative stress state detection}

Both liver and lung tissues were weighed and 10\% homogenates of the tissues were collected with $0.9 \% \mathrm{NaCl}$ by mortar. The homogenates were centrifuged at $4{ }^{\circ} \mathrm{C}$ and then the supernatant was collected. The MDA and GSH content was determined by MDA and GSH detection kits, respectively.

\section{Pathological observation}

All the liver and small intestine tissue was taken from each mouse and fixed for $72 \mathrm{~h}$ with $10 \%$ neutral formalin solution. The slices were dehydrated, waxsealed, sectioned and stained with haematoxylin and eosin successively to observe the pathological changes with an optical microscope.

\section{Data processing}

Data were processed by SPSS 12.0 analysis software. All measurements are expressed as the mean \pm standard deviation and were subjected to one-way analysis of variance (ANOVA) followed by Fisher's least significant difference (LSD) comparison.

\section{RESULTS}

\section{Effects of Hep-SOD on the organ indices of irradiated mice}

Both spleen and thymus indices of mice decreased by various degrees in the irradiated control group. The results showed that decline of spleen and thymus indices was inhibited effectively by amifostine and high and medium dosages of Hep-SOD. Data are shown in Table I.

\section{Effects of Hep-SOD on haematopoietic function}

Our experiments showed that the BMNC and DNA content of bone marrow in 6 Gy-irradiated mice were decreased significantly compared with those of mice in the normal control group without radiation $(P<0.01)$. When the mice were irradiated, CFU-S of the irradiated mice began to increase with Hep-SOD treatment. Data are shown in Table II. CFU-S increased with the increase of Hep-SOD dosage. When mice were treated with amifostine and high and medium dosages of Hep-SOD, the decrease of BMNC and DNA content were reversed notably. There was no significant difference between the marrow DNA content of the mice in the amifostine- and high and medium dosages of Hep-SOD-treated groups and that of the mice in the normal control group (Table II).

\section{Effects of Hep-SOD on peripheral blood cell count of irradiated mice}

The results showed that all complete blood counts of mice in the irradiated control group decreased after radiation (Table III). There were statistical differences 
TABLE I - Spleen index and thymus index of the mice in different groups $(n=8, \bar{x} \pm s, \mathrm{mg} / \mathrm{g})$

\begin{tabular}{lcc}
\hline Group & Spleen index $(\mathbf{m g} / \mathbf{g})$ & Thymus index $(\mathbf{m g} / \mathbf{g})$ \\
\hline Normal control group & $5.33 \pm 0.55^{* *}$ & $2.36 \pm 0.72^{*}$ \\
6Gy irradiated group & $2.14 \pm 1.03^{\# \#}$ & $1.40 \pm 0.19^{\#}$ \\
Amifostine(300mg/kg)+6Gy & $3.17 \pm 0.38^{* \#}$ & $1.91 \pm 0.07^{* \#}$ \\
SOD $(35000 \mathrm{U} / \mathrm{kg})+6 \mathrm{~Gy}$ & $2.56 \pm 0.54^{\# \#}$ & $0.86 \pm 0.02^{\# \#}$ \\
Hep-SOD(70000U/kg)+6Gy & $4.09 \pm 0.55^{* *}$ & $2.15 \pm 0.67^{*}$ \\
Hep-SOD(35000U/kg)+6Gy & $3.81 \pm 0.49^{* *}$ & $2.12 \pm 0.94^{*}$ \\
Hep-SOD $(17500 \mathrm{U} / \mathrm{kg})+6 \mathrm{~Gy}$ & $2.12 \pm 0.73^{\# \#}$ & $1.13 \pm 0.20^{\#}$ \\
\hline
\end{tabular}

Notes: ${ }^{*} P<0.05,{ }^{* *} P<0.01$, compared with irradiated control group. ${ }^{\sharp} P<0.05$, ${ }^{\#} P<0.01$, compared with normal control group.

TABLE II - Haematogenesis function indexes of the mice in different groups $(\mathrm{n}=8, \bar{x} \pm s)$

\begin{tabular}{lccc}
\hline Group & CFU-S (/spleen) & BMNC $(\times \mathbf{1 0}$ /femur) & $\begin{array}{c}\text { DNA content of marrow } \\
\text { (A/ femur) }\end{array}$ \\
\hline Normal control group & $1.25 \pm 1.39^{* *}$ & $6.42 \pm 2.84^{* *}$ & $0.86 \pm 0.12^{* *}$ \\
6 Gy irradiated group & $26.67 \pm 6.11^{\# \#}$ & $0.77 \pm 0.54^{\# \#}$ & $0.13 \pm 0.01^{\# \#}$ \\
Amifostine(300mg/kg)+6 Gy & $50.50 \pm 11.26^{* * \#}$ & $2.38 \pm 1.25^{* * \#}$ & $0.78 \pm 0.12^{* *}$ \\
SOD (35000U/kg)+6 Gy & $36.33 \pm 5.86^{\# \#}$ & $2.76 \pm 1.11^{* * \# \#}$ & $0.70 \pm 0.35^{* * \#}$ \\
Hep-SOD(70000U/kg)+6 Gy & $57.33 \pm 1.97^{* * \#}$ & $5.02 \pm 2.45^{* * \#}$ & $0.82 \pm 0.09^{* *}$ \\
Hep-SOD(35000U/kg)+6 Gy & $51.20 \pm 3.27^{* * \# \#}$ & $2.24 \pm 1.55^{* \# \#}$ & $0.81 \pm 0.26^{* *}$ \\
Hep-SOD(17500U/kg)+6 Gy & $31.00 \pm 7.44 \# \#$ & $1.82 \pm 0.97^{* \#}$ & $0.62 \pm 0.29^{* \#}$ \\
\hline
\end{tabular}

Notes: ${ }^{*} P<0.05,{ }^{* *} P<0.01$, compared with irradiated control group. ${ }^{\sharp} P<0.05$, ${ }^{\#} P<0.01$, compared with normal control group.

in WBC, RBC, PLT and LY between the high dosage Hep-SOD-treated group and the irradiated control group $(P<0.05)$.

\section{Effects of Hep-SOD on liver function of irradiated mice}

Data are shown in Figure 1. The activity of GPT and GOT in peripheral blood increased significantly after radiation, and was lowered by amifostine and high and medium dosages of Hep-SOD. The GPT activity of mice in the high and medium dosages of Hep-SODtreated groups could be kept at the same level as that of the normal control group so we can deduce that HepSOD can protect liver function from radiation damage.

\section{Effects of Hep-SOD on MDA and GSH in liver and lung tissue of irradiated mice}

The MDA content in lung tissue of mice in both the amifostine-treated group and the high dosage of HepSOD-treated group was lower than that in the irradiated control group $(P<0.01)$, while there was no difference between each treated group. The GSH content of the mice in the amifostine-, SOD-, and high and medium dosages of Hep-SOD-treated groups was higher than that in the

TABLE III - Peripheral blood cell counts of the mice in different groups $(\mathrm{n}=8, \bar{x} \pm s)$

\begin{tabular}{lcccc}
\hline Group & $\begin{array}{c}\text { WBC } \\
\left(\times \mathbf{1 0}^{9} / \mathbf{L}\right)\end{array}$ & $\begin{array}{c}\mathbf{R B C} \\
\left(\times \mathbf{1 0}^{1 \mathbf{2}} / \mathbf{L}\right)\end{array}$ & $\begin{array}{c}\text { PLT } \\
\left(\times \mathbf{1 0}^{9} / \mathbf{L}\right)\end{array}$ & $\begin{array}{c}\mathbf{L Y} \\
(\times \mathbf{1 0} / \mathbf{L})\end{array}$ \\
\hline Normal control group & $8.48 \pm 1.22^{* *}$ & $7.84 \pm 0.48^{*}$ & $517.38 \pm 134.26^{* *}$ & $5.42 \pm 2.36^{* *}$ \\
6Gy irradiated group & $2.01 \pm 1.65^{\# \#}$ & $6.21 \pm 0.61^{\#}$ & $284.75 \pm 87.89^{\#}$ & $1.04 \pm 0.71^{\# \#}$ \\
Amifostine(300mg/kg)+6Gy & $3.08 \pm 0.27^{\# \#}$ & $6.31 \pm 0.65^{\#}$ & $309.00 \pm 52.10^{\#}$ & $1.33 \pm 0.28^{\# \#}$ \\
SOD(35000U/kg)+6Gy & $2.82 \pm 0.57^{\# \#}$ & $6.21 \pm 2.38^{\#}$ & $241.80 \pm 70.43^{\#}$ & $0.31 \pm 0.06^{\# \#}$ \\
Hep-SOD(70000U/kg)+6Gy & $3.42 \pm 0.20^{* \# \#}$ & $7.30 \pm 0.90^{*}$ & $367.00 \pm 52.09^{* \#}$ & $2.09 \pm 0.97^{* \#}$ \\
Hep-SOD(35000U/kg)+6Gy & $2.98 \pm 0.70^{\# \#}$ & $7.44 \pm 0.55^{*}$ & $354.67 \pm 52.37^{* \#}$ & $1.87 \pm 0.18^{\# \#}$ \\
Hep-SOD(17500U/kg)+6Gy & $2.64 \pm 1.84^{\# \#}$ & $7.40 \pm 0.47^{*}$ & $303.60 \pm 68.44^{\#}$ & $1.63 \pm 0.86^{\# \#}$ \\
\hline
\end{tabular}

Notes: ${ }^{*} P<0.05,{ }^{* *} P<0.01$, compared with irradiated control group. ${ }^{\sharp} P<0.05,{ }^{\#} P<0.01$, compared with normal control group. 


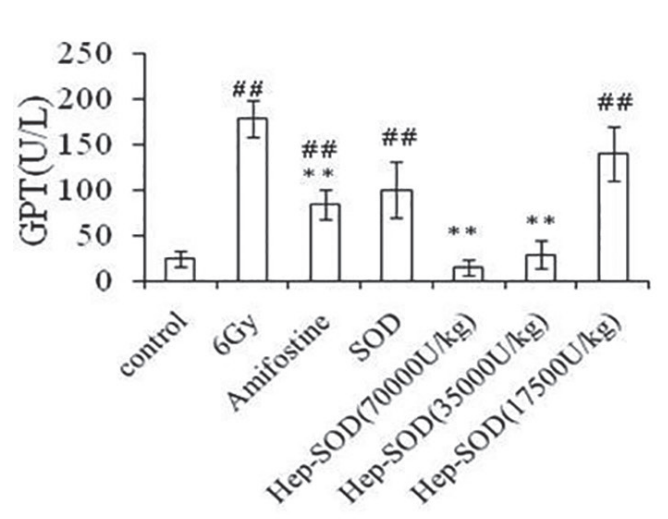

A

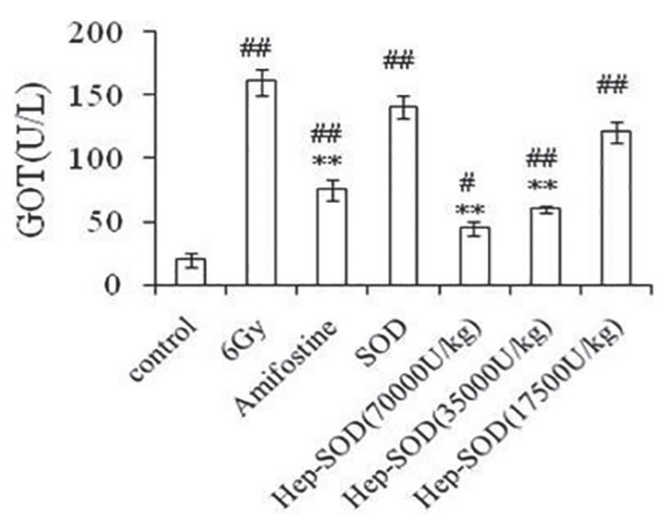

$\mathrm{B}$

FIGURE 1 - GPT (A) and GOT (B) activity in the peripheral blood of irradiated mice in different groups. Notes: GPT and GOT activity of 56 mice in different groups was detected, with eight mice in each group. ${ }^{*} P<0.05,{ }^{*} P<0.01$, compared with the irradiated control group. ${ }^{\#} P<0.05,{ }^{\#} P<0.01$, compared with the normal control group.

irradiated control group $(P<0.01)$. All the data are shown in Figures 2 and 3. On the other hand, the content of both MDA and GSH in the liver of mice was not significantly affected by Hep-SOD.

\section{Effects of Hep-SOD on the tissue of irradiated mice}

\section{Liver tissue}

The structure of the hepatic sinusoids, hepatic plate, hepatic lobules and hepatic cells of mice in the normal control group was regular (Figure 4A). There was mild dilatation and hyperaemia in part of the hepatic sinusoids with central vein wall thickening and oedema. Loose, empty cytoplasm and obvious conjugated nuclei appeared in the liver tissue of mice in the irradiated control group
(Figure 4B). Necrosis of partial liver cells indicated the serious consequences of radiation. There was liver sinus congestion and liver cell swelling in the mice of the amifostine-treated group (Figure 4C), while the structure of hepatic lobules, hepatic sinusoids, hepatic plates and liver cells was regular with a few regional hepatic sinusoidal dilatations in the mice of the SOD- (Figure 4D) and high and medium dosages of Hep-SOD-treated groups (Figure 4E and 4F). There was occasional liver cell swelling, spotty necrosis and dilated congestive in a minority of liver tissue in mice of the low dosage of HepSOD-treated group (Figure 4G). All the data in Figure 4 were blindly scored by pathology professors according to the Roussel Uclaf Causality Assessment Method (RUCAM), which showed that there was little damage in mice of the high dosage of Hep-SOD-treated irradiated

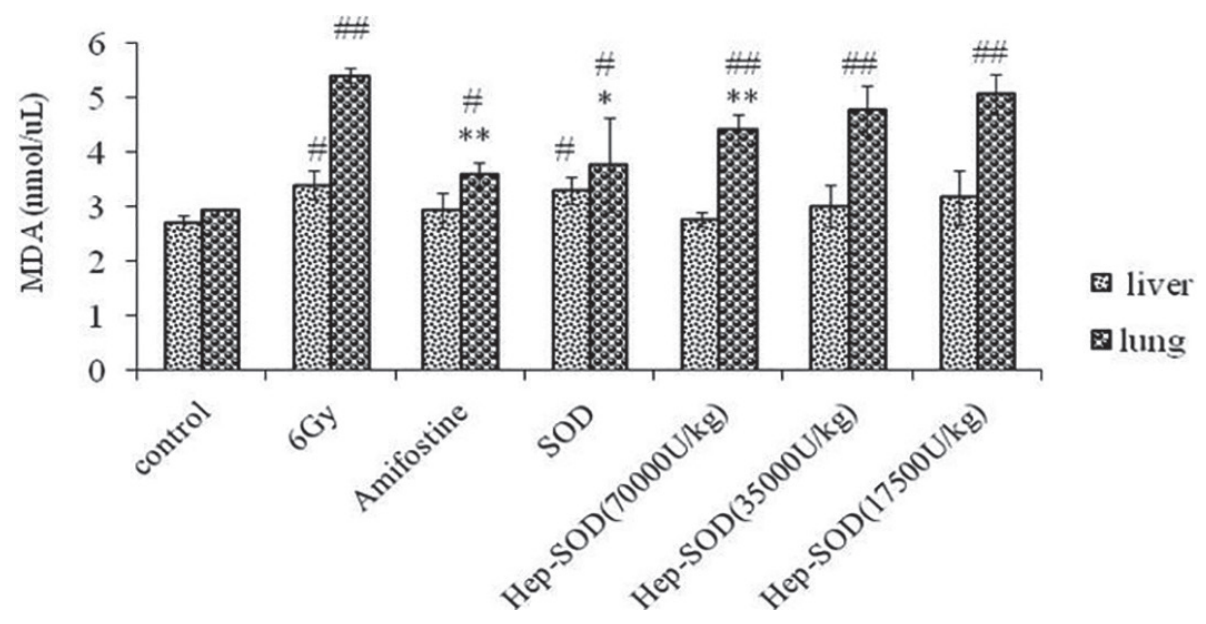

FIGURE 2 - MDA content in the liver and lung of irradiated mice in different groups. Notes: MDA content of 56 mice in different groups was detected, with eight mice in each group. ${ }^{*} P<0.05$, $* * P<0.01$, compared with the irradiated control group. ${ }^{*} P<0.05$, ${ }^{\#} P<0.01$ compared with the normal control group. 


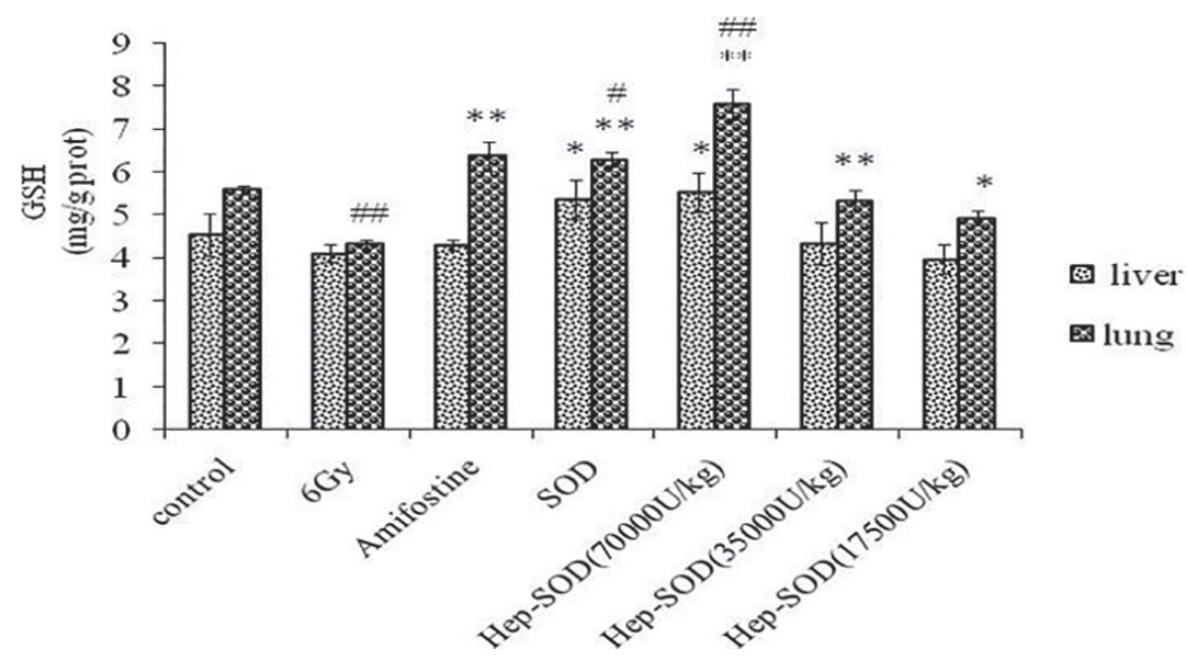

FIGURE 3 - GSH content in the liver and lung of irradiated mice in different groups. Notes: GSH content of 56 mice in different groups was detected, with eight mice in each group. ${ }^{*} P<0.05,{ }^{* *} P<0.01$, compared with the irradiated control group. ${ }^{*} P<0.05$, ${ }^{\#} P<0.01$, compared with the normal control group.

group (Table IV). Little difference lay between mice of the normal control group and those of the high dosage of Hep-SOD-treated irradiated group.

\section{Small intestine tissue}

No pathological changes were found in the mucosa, submucosa, muscular layer or adventitia layer of the small intestine in the mice of the normal control group, amifostine-, SOD- or high and medium dosage of HepSOD-treated irradiated groups. There was some regional oedema, hyperaemia, occasional intestinal epithelial cell shedding and nuclear pyknosis in mice of the irradiated control group, while there was sub-regional oedema and hyperaemia lesions in part of the small intestine in mice of the low dosage of Hep-SOD-treated group.

\section{DISCUSSION}

The efficacy of SOD in preventing radiationinduced damage has been demonstrated by a series of studies. Delanian et al. (1994) and Lefaix et al. (1996) demonstrated that the intramuscular injection of liposomal $\mathrm{Cu}, \mathrm{Zn}$-SOD could decrease skin fibrosis in an animal model and a human clinical trial (Pan et al., 2012), but SOD has shortcomings such as a short halflife, antigenicity and instability (Liu et al., 2009a) so our
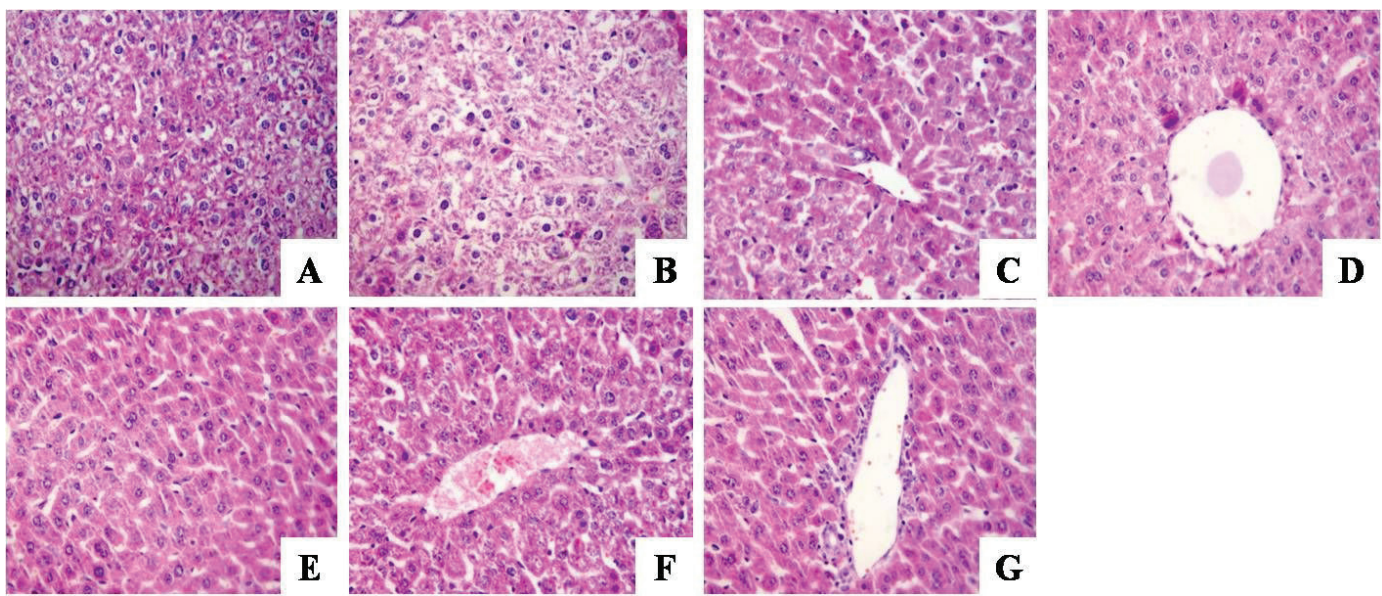

FIGURE 4 - Histopathology of liver tissue of the mice in different groups $(\times 200)$, with eight mice in each group. (A) Normal control group. (B) Irradiated control group. (C) Amifostine-treated irradiated group. (D) SOD-treated irradiated group. (E) High dosage of Hep-SOD-treated irradiated group. (F) Medium dosage of Hep-SOD-treated irradiated group. (G) Low dosage of HepSOD-treated irradiated group. 
The radiation protection role of heparin-SOD conjugate in irradiated mice

TABLE 4 - Blind scores of the liver injury in different section of mice by pathologists

\begin{tabular}{|c|c|c|c|c|c|c|c|c|c|}
\hline \multirow{2}{*}{ Group } & \multicolumn{8}{|c|}{ Number of the mice } & \multirow{2}{*}{ Average } \\
\hline & 1 & 2 & 3 & 4 & 5 & 6 & 7 & 8 & \\
\hline $\bar{A}$ & 0 & -1 & 0 & -1 & 0 & 0 & 0 & 0 & -0.25 \\
\hline B & 9 & 8 & 9 & 8 & 9 & 9 & 8 & 8 & +8.50 \\
\hline $\mathrm{C}$ & 3 & 2 & 2 & 2 & 2 & 3 & 2 & 3 & +2.38 \\
\hline $\mathrm{D}$ & 2 & 1 & 1 & 1 & 1 & 2 & 1 & 2 & +1.38 \\
\hline E & 1 & 1 & 0 & 1 & 1 & 0 & 1 & 1 & +0.75 \\
\hline $\mathrm{F}$ & 2 & 3 & 2 & 1 & 1 & 2 & 2 & 2 & +1.88 \\
\hline G & 2 & 2 & 3 & 3 & 1 & 3 & 3 & 2 & +2.38 \\
\hline
\end{tabular}

Notes: (A) Normal control group. (B) Irradiated control group. (C) Amifostine treated irradiated group. (D) SOD treated irradiated group. (E) High dosage of Hep-SOD treated irradiated group. (F) Medium dosage of Hep-SOD treated irradiated group. (G) Low dosage of Hep-SOD treated irradiated group. The scores are divided into ranges that represent highly probably $(>8)$, probable $((6-8)$, possible (3-5), unlikely (1-2), and excluded $(\leq 0)$, according to the use and limitations of RUCAM.

team managed to modify SOD with heparin. Our earlier studies showed that Hep-SOD conjugate can attenuate bleomycin-induced pulmonary fibrosis in vivo, and inhibit the inflammatory cytokine expression mediated by free radicals and DNA damage induced by $\gamma$-radiation (Varani, Ward, 1994; Liu et al., 2009b). In this paper, a Kunming mouse acute radiation-induced injury model was constructed successfully to determine the effects of Hep-SOD conjugate on radiation protection in vivo. The results of pilot experiments showed that vehicle injection had no effect on the outcomes measured. HepSOD has radio-protective effects on mice. Bone marrow suppression is mainly shown as symptoms including reduction of peripheral blood cell and haemoglobin content, and atrophy of the thymus gland and spleen induced by inhibition of lymphocytes (Heffner, Repine, 1989). When radiation occurs, such immune organs as the thymus, spleen and liver can restore haematopoietic function and play a compensatory role in extra medullary haematopoiesis, while occurrence of CFU-S is one of the significant symptoms in the spleen. When treated with high and medium dosages of Hep-SOD, the decrease of BMNC and DNA content was reduced notably. Whether and how Hep-SOD conjugate integrates the antioxidant capacity of SOD and heparin is worthy of further study.

Both MDA and GSH were characterized as the extent of oxidative injury and reduction-oxidation (redox) state of organisms (Varani, Ward, 1994). The results showed that MDA content in the lungs of mice of all the treated groups was lower than that of the mice in the irradiated control group, and the difference between the amifostine-treated group, the high dosage Hep-SODtreated group and the irradiated group was significant $(P<0.01)$. It is well known that oxidative stress and endothelial cell injury often cause many pathological symptoms (Tsukamoto et al., 2011), of which lung injury is one of the most commonly associated symptoms (Freeman, Crapo, 1982; Siflinger-Birnboim, Malik, 1993). The reason may lie in the sensitivity of endothelial cells to ROS in pulmonary tissue at a systemic level. Therefore, in inflammation and activation of leukocytes, the release of large amounts of ROS into endothelial cells leading to lung injury is the most common complication (Clawson, 1989). GSH in the liver did not change significantly after radiation. This study shows that HepSOD may prevent lung tissue from radiation-induced damage.

When oxidative damage occurs, the membrane permeability of myocardial cells and liver cells will change accordingly so that the two intracellular enzymes, GPT and GOT, of the heart and liver will be released into the blood (Gao et al., 2008). The activity of GPT and GOT in blood was lowered significantly after amifostine and high and medium dosages of Hep-SOD treatment, indicating their protective effects on liver function from radiation-induced damage. The short-term effects of Hep-SOD on Kunming mice were studied in this manuscript systematically. The survival rate, weight analysis of all the mice 30 days after radiation and dose modifying factor (DMF) of Hep-SOD need to be further studied. The long-term effects of HepSOD on radiation-induced damage need to be investigated in future research. Gao et al. (2008) reported that $\mathrm{Cu}, \mathrm{Zn}$ SOD can downregulate the activity of cyclin B1 and inhibit the direct conversion of $\mathrm{G} / \mathrm{M}$ in order to prevent cells from damage caused by radiation. On the other hand, the control animals did not receive any vehicle in the experiment. Although no impact on the mice was found during the pilot experiment, the experiment would be better if the 
mice in the control group received the same vehicle as the other treated mice.

\section{CONCLUSIONS}

The bone marrow suppression of irradiated mice could be reduced obviously when treated by Hep-SOD before radiation. All the results showed that the damage caused by radiation was relieved when the mice were treated by Hep-SOD before radiation so Hep-SOD is a potential drug to prevent organisms from the damage caused by radiation. The mechanism of Hep-SOD also needs to be further studied to clarify how Hep-SOD reduces the radiation-induced damage in vivo.

\section{ACKNOWLEDGEMENTS}

The liver injury data were blindly scored by the group of Professor Weidong Zhang, Shandong Academy of Medical Sciences. This work was supported by the Major Projects of Science and Technology of Shandong Province (no. 2015ZDJS04001) and the Development Fund for Collaborative Innovation Centre of Glycoscience of Shandong University.

\section{REFERENCES}

Adachi T, Hara H, Yamada H, Yamazakic N, Yamamoto $\mathrm{M}$, Sugiyama T, et al. Heparin-stimulated expression of extra cellular superoxide dismutase in human fibroblasts. Atherosclerosis. 2001;159(2):307-12.

Aghajanyan A, Kuzmina N, Sipyagyna A, Baleva L, Suskov I. Analysis of genomic instability in the offspring of fathers exposed to low doses of ionizing radiation. Environ Mol Mutagen. 2011;52(7):538-46.

Aghajanyan A, Suskov I. Transgenerational genomic instability in children of irradiated parents as a result of the Chernobyl Nuclear Accident. Mutat Res. 2009;671(1-2):52-7.

Alamri OD, Cundy AB, Di Y, Jha AN, Rotchell JM. Ionizing radiation-induced DNA damage response identified in marine mussels, Mytilus sp. Environ Pollut. 2012;168:107-12.

Asselot-Chapel C, Combacau L, Labat-Robert J, Kern P. Expression of fibronectin and interstitial collagen genes in smooth muscle cells: modulation by low molecular weight heparin fragments and serum. Biochem Pharmacol. 1995;49(5):653-9.
Bioteux S, Guillet M. Abasic sites in DNA: repair and biological consequences in Saccharomyces cerevisiae. DNA Repair. 2004;3(1):1-12.

Bölling T, Geisenheiser A, Pape H, Martini C, Rübe C, Timmermann B, et al. Hypothyroidism after head and neck radiotherapy in children and adolescents: preliminary results of the registry for the evaluation of side effects after radiotherapy in childhood and adolescence (RISK). Int J Radiat Oncol Biol Phys. 2011;81(5):787-91.

Castellot JJ, Wong K, Herman B, Hoover RL, Albertini DF, Wright TC, et al. Binding and internalization of heparin by vascular smooth muscle cells. J Cell Physiol. 1985;124(1):1320.

Clawson GA. Mechanisms of carbon tetrachloride hepatotoxicity. Pathol Immunopathol Res. 1989;8(2):104-12.

Davis TA, Mungunsukh O, Zins S, Day RM, Landauer MR. Genistein induces radioprotection by hematopoietic stem cell quiescence. Int J Radiat Biol. 2008;84(9):713-26.

Delanian S, Baillet F, Huart J, Lefaix JL, Maulard C, Housset M. Successful treatment of radiation-induced fibrosis using liposomal $\mathrm{Cu}, \mathrm{Zn}$ superoxide dismutase: clinical trial. Radiother Oncol. 1994;32(1):12-20.

Echeveste P, Agustí S, Dachs J. Cell size dependence of additive versus synergetic effects of UV radiation and PAHs on oceanic phytoplankton. Environ Pollut. 2011;159(5):1307-16.

Freeman BA, Crapo JD. Biology of disease: free radicals and tissue injury. Lag Invest. 1982;47(5):412-26.

Gao Z, Sarsour EH, Kalen AL, Li L, Kumar MG, Goswami PC. Late RO accumulation and radio-sensitivity in SOD1overexpressing human glioma cells. Free Radic Biol Med. 2008;45:1501-9.

Georg P, Kiristits C, Goldner G, Dörr W, Hammer J, Pötzi R, et al. Correlation of dose-volume parameters, endoscopic and clinical rectal side effects in cervix cancer patients treated with definitive radiotherapy including MRI-based brachytherapy. Radiother Oncol. 2009;91(2):173-80.

Habeeb AF. Determination of free amino groups in proteins by trinitrobenzene sulfonic acid. Anal Biochem. 1966;14(3):32836. 
The radiation protection role of heparin-SOD conjugate in irradiated mice

Heffner JE, Repine JE. Pulmonary strategies of antioxidant defense. Am Rev Respir Dis. 1989;140(2):531-54.

Lefaix JL, Delanian S, Leplat JJ, Tricaud Y, Martin M, Nimrod A, et al. Successful treatment of radiation-induced fibrosis using $\mathrm{Cu}, \mathrm{Zn}-\mathrm{SOD}$ and Mn-SOD: an experimental study. Int $J$ Radiat Oncol Biol Phys. 1996;35(2):305-12.

Liu JF, Tan HN, Sun Y, Zhou S, Cao JC, Wang FS. The preventive effects of heparin-superoxide dismutase on carbon tetrachloride-induced acute liver failure and hepatic fibrosis in mice. Mol Cell Biochem. 2009c;327(1-2):219-28.

Liu JF, Teng L, Liu CH, Hu L, Wang Y, Liu H, Wang FS. Argument delivery of superoxide dismutase to macrophages by the chemical modification with polysaccharide and attenuation effects on radiation-induced inflammatory cytokine expression in vitro. J Drug Target. 2009a;17(3):216-24.

Liu JF, Wang X, Tan HN, Liu H, Wang YG, Chen RQ, et al. Effect of heparin-superoxide dismutase on $\gamma$-radiation induced DNA damage in vitro and in vivo. Drug Discov Ther. 2010a;4(5):355-61.

Liu JF, Wang X, Wang FS, Teng L, Cao JC. Attenuation effects of heparin-superoxide dismutase on conjugate on bleomycin-induced lung fibrosis in vivo and radiationinduced inflammatory cytokine expression in vitro. Biomed Pharmacother. 2009b;63(7):484-91.

Liu JF, Zhao T, Tan HN, Cheng YN, Cao JC, Wang FS. Pharmacokinetic analysis of in vivo disposition of heparin-superoxide dismutase. Biomed Pharmacother. 2010b;64(10):686-91.

Ma H, Wallis LK, Diamond S, Li S, Canas-Carrell J, Parra A. Impact of solar $\mathrm{UV}$ radiation on toxicity of $\mathrm{ZnO}$ nanoparticles through photocatalytic reactive oxygen species (ROS) generation and photo-induced dissolution. Environ Pollut. 2014;193:165-72.

Nabout R, Martin M, Remy J, Robert L, Lafuma C. Heparin fragments modulate the collagen phenotype of fibroblasts from radiation-induced subcutaneous fibrosis. Exp Mol Pathol. 1989;51(2):111-22.

Nornura K, Imai H, Koumura T, Nakagawa Y. Mitochondrial phospholipid hydroperoxide glutathione peroxidase inhibits the release of cytochrome $\mathrm{C}$ from mitochondria by suppressing the peroxidation of cardiolipin in hypoglycaemia-induced apoptosis. Biochem J. 2000;351(1):183-93.
Pan JR, Su Y, Hou XJ, He HC, Liu ST, Wu JX, et al. Protective effect of recombinant protein SOD-TAT on radiation-induced lung injury in mice. Life Sci. 2012;91(3-4):89-93.

Petkau A, Chelack WS, Pleskach SD. Protection of superoxide dismutase of white blood cells in X-irradiated mice. Life Sci. 1978;22(10):867-82.

Qi JZ, Wang FS, Zhang HW, Cao JC, Zhang TM. Chemical modification of superoxide dismutase by low molecular weight heparin and their physical and chemical properties. J China Pharm. 2006;41:150-3.

Rooney JP, Patil A, Zappala MR. Conklin DS, Cunningham RP, Begley TJ. A molecular bar-coded DNA repair resource for pooled toxic genomic screens. DNA Repair. 2008;7(11):185568.

Siflinger-Birnboim A, Malik AB. Neutrophil adhesion to endothelial cells impairs the effects of catalase and glutathione in preventing endothelial injury. J Cell Physiol. 1993;155(2):2349.

Simonnet AJ, Nehmé J, Vaigot P, Barroca V, Leboulch P, TronikLe Roux D. Phenotypic and functional changes induced in hematopoietic stem/progenitor cells after gamma-ray radiation exposure. Stem Cells. 2009;27(6):1400-9.

Tsukamoto A, Higashiyama S, Yoshida K, Watanabe Y, Furukawa KS, Ushida T. Stable cavitation induces increased cytoplasmic calcium in $\mathrm{L} 929$ fibroblasts exposed to $1-\mathrm{MHz}$ pulsed ultrasound. Ultrasonics. 2011;51(8):982-90.

Tyagi SC, Kumar S, Katwa L. Differential regulation of extracellular matrix metalloproteinase and tissue inhibitor by heparin and cholesterol in fibroblast cells. J Mol Cell Cardiol. 1997;29(1):391-404.

Varani J, Ward PA. Mechanisms of endothelial cell injury in acute inflammation. Shock. 1994;2(5):311-9.

Zhang HW, Wang FS, Shao W, Zheng XL, Qi JZ, Cao JC, et al. Characterization and stability investigation of $\mathrm{Cu}, \mathrm{Zn}$-superoxide dismutase covalently modified by low molecular weight heparin. Biochem (Moscow). 2006;71(Suppl 1):S96-100.

Received for publication on $26^{\text {th }}$ February 2017 Accepted for publication on $06^{\text {th }}$ July 2017 